\title{
ANALYZING THE OPPORTUNITIES OF DigitAL MARKETING IN BANGLADESH TO PROVIDE AN EFFICIENT INTERRELATION BETWEEN BUSINESS ORGANIZATION AND CONSUMER
}

\author{
Farjana Akter ${ }^{1}$, Zayed- Us- Salehin ${ }^{1}$, Abul Kalam Azad ${ }^{2}$ and Sultana Jahan Soheli ${ }^{1}$ \\ ${ }^{1}$ Department of Information and Communication Engineering, Noakhali Science and \\ Technology University, Noakhali, Bangladesh \\ ${ }^{2}$ Department of Computer Science and Telecommunication Engineering, Noakhali \\ Science and Technology University, Noakhali, Bangladesh
}

\begin{abstract}
The idea of marketing recently converging to Digital marketing and digital marketing is becoming the most effective means for building business-customer relationships with long-term loyalty. It is a matter of concern that how this convergence is taking place in developing countries like Bangladesh. In this paper, the impact of digital marketing on the customer engagement with products and brands is investigated using descriptive research method and is based on survey. This study attempts to find the most effective form of digital marketing in Bangladesh by taking responses using questionnaires from sample, which has been used as the primary data. This study aims to discover the factors that work background to make the customers loyal to the brand and to have a positive attitude toward brand. It also illustrates about the differences of traditional marketing and digital marketing and the changes brought by digital marketing in brands relationship marketing. Analysis of survey output shows that there is an overall positive influence of internet advertising on consumer purchase decision. It is recommended that companies should conduct a market research on different markets in various countries to identify more specific market related and regional factors.
\end{abstract}

\section{KEYWORDS}

Digital Marketing, Customer Behaviour, Brand, Business- customer Relationship

\section{INTRODUCTION}

The world is constantly changing and the perceptions of distance and time are being influenced by it. The whole world is now virtually connected where access to the Internet and just a couple of clicks, are enough to be communicate with anyone. The Internet and online shopping has introduced a completely new horizon of marketing, evolved strategies and different types of it. This new marketing domain built upon the Internet arena full of skillful and convenient promotional tools now dominating television and radio based marketing. Not only perceptions of distance and time but also expectations and behavior of customers have changed since the foundation of the Internet.

Recently, marketers are turning away from traditional source of advertising due to the desire for having more control over the contents and getting more direct or indirect interaction with the targeted customers. As traditional advertising is normally unidirectional and takes time to realize the response of customers, more quick feedback opportunity provided by the Internet makes 
digital marketing a precious one. On the other hand, consumers prefer on-demand and immediate access to information at their own convenience.

It has now become a habit of people to check their social media accounts time to time and during those checking they use those media to conduct their information searches and to make their purchasing decisions. This extensive use of the social Web is an increasingly important factor to marketers. It seems that consumers also perceive social media as a more trustworthy source of information regarding products and services than traditional elements of advertising [1]. The feeling of trust comes from the fact that there are option of checking reviews of other customers of the particular products and service.

It is obvious that the effect of digital marketing on customer purchase decision is not the same throughout the world and varies from country to country. In developing countries like Bangladesh where most of the people surf Internet using smart phones and are not technically that much skilled, it will not be ideal to choose a random group of people to collect sample data for online marketing related study. Here a large number of people are not even familiar with eshopping and e-marketing, which leads to a careful selection of respondents to collect data for this type of research.

In this study, most of the respondents are university undergraduate students, as it is expected them to be more intimate with online shopping and marketing.

\section{Problem Statement}

Consumers worldwide are price sensitive but their consumptions are merely driven by pricefactors. Nowadays, they are more and more cautious on their spending regarding quality, safety, branding, price etc. Retailers are also realizing that the value of trust of the customers on them is an important asset for gaining better profitable turnover. Digital marketing offers a set of powerful tools and methodologies for promoting products and services through the Internet. It includes a wider range of marketing elements than traditional business marketing due to the extra channels and marketing mechanisms available on the Internet. It may foster the growth of trust and relationship between consumer and brand, which making it increasingly important medium to utilize in order to maximize brand loyalty throughout the world. But the pattern of this growth may depend on some factors and this dependency may vary regionally. For efficient evaluation of the most influencing factors for a specific region, region wise study is essential.

\section{RELATED WORKS}

Regarding the highly growing use of digital marketing throughout the world, several survey based study has been performed in both local and global context to investigate the impact of digital marketing on consumers and to identify the most effective ways to create and boost brand equity.

In [2], authors examined the relationship between customer relationship marketing and customer satisfaction by conducting a survey on a sample of one hundred and seven customers from three mobile service providing companies such as Airtel, Dialog, and Mobitel in Sri Lanka. They used Correlation and regression analysis to measure relationship.

In [3], authors analyzed the impact of brand awareness on consumer behavior. It was revealed from the study that traditional media and social media both positively influence the brand awareness. They studied four dimensions of consumer's based-brand equity specifically brand 
awareness, brand image, perceived quality and brand loyalty by distributing questionnaires and found brand loyalty seems to have the minimum brand equity rating by consumers.

A survey study based on responses of 200 consumers was performed in [4] to identify the impact of the online Internet and digital media marketing strategies in creating the brand loyalty and retaining the existing and new customers. Results of the study affirmed that internet is useful marketing tool which helps and assist the companies to target specific and their targeted audience to promote their brand or product and also retain their new and existing consumers. The study also revealed that people are influenced by the marketing strategies used by the companies based on the internet and digital media and those facilitate the companies and brands to increase their popularity and make loyal customers.

Another work is done in [5] to study the influences of advertisement, both traditional modern media (blogs, websites, SMS etc) on consumer buying behavior. The authors introduced a combination of different variables, namely Entertainment, Familiarity, Social Imaging, Spending, Consumer Buying Behavior, and attempted to examine their influence on consumer behavior and also determine which of these variables carries the most influencing. They found Familiarity and Entertainment have the most significant impact.

An efficient approach for predicting accurate sentiment from raw unstructured data in order to extract opinions from the Internet and predict online customers preferences was proposed in [6], which could be valuable and crucial for economic and marketing researchers. The authors developed a system which is able to identify and classify sentiment represented in an electronic text from tweets in Twitter. They used tweepy to access Twitters Streaming API and combined natural language processing techniques with naive Bayes networks to classify users data, used GIS (geographical information system) and Matplotlib for data visualization and displaying the results.

Another attempts was made in [7] to review the literature of the application of social media for marketing promotion. The authors tried to provide a conclusive evidence that the promotion through social media is better than the traditional promotion approach. They also tried to predict the future path of social media marketing.

In [8], the authors aimed to find the most preferred tool of digital marketing among Search engine optimization (SEO), Search engine marketing (SEM), Social Media Marketing (SMM) and Payper-click advertising (PPC). They found Social Media Marketing be the most powerful channel for businesses to reach customers and promote brands.

Similar work is done in [9] where the authors analyzed the use of website, Internet advertising, social networks and the search engine optimization as online marketing tool so that companies can identify the most effective online marketing tools in developing their brand awareness.

In [10], authors examined the influence of efficient online marketing, effective communication, and on-time delivery on the regularity of visits and consumer patronage of the three selected online stores in Owerri, Imo State, Nigeria. They used Statistical Package for Social Sciences (SPSS) software to analyze the data collected from 300 respondents and found that online marketing is a viable marketing communication channel which has significant effect on the regularity of visits and consumer patronage of online stores.

Another study is done in [11] to examine the implication of digital marketing in consumer purchase decision and to find out that the consumers are aware of digital marketing and the 
International Journal of Managing Information Technology (IJMIT) Vol.12, No.3, August 2020

digital channels influence in their purchase decision. The study was carried out through survey from 50 respondents and results were analyzed using chi square test. The findings revealed that customers are aware of digital marketing and they prefer to by electronic and shopping goods through digital channels in their purchase behavior.

In [12], a unique framework of consumer-brand relationship from experiential and identification perspective was presented and tested. Testing was done through survey and results reveal that the various dimensions of brand experience have a different influence on the two components of consumer-brand relationship, which are two-way communications and emotional exchange, across product and service brand categories.

This study focuses on how digital marketing influences customers' decision of purchase and their relationship to a brand in Bangladesh. Within the past of few years, digital marketing has become increasingly popular medium for brand and customer engagements. It will be helpful for companies to know the most effective way to reach the customers through digital marketing, which is the main concern of this survey based study.

\section{QUESTIONNAIRE DESIGN}

\subsection{Use of Google form}

Google form is a simple and frequently used online tool for creating questionnaires for online surveys and has been used in this survey based study because of its easy interface and built in visualization of the outcomes in a simplified manner.

\subsection{Question categorization}

The questionnaires designed for this research is categorized based on which particular factor a specific question targets to reflect. This categorization is shown in Table 1.

Table 1. Question categorization

\begin{tabular}{|l|l|}
\hline Targeted Factor & Questions \\
\hline Demographic factors & Q1,Q2 \\
\hline Classify respondents & Q3,Q4 \\
\hline Loyalty & Q5 \\
\hline Intention & Q6,Q7 \\
\hline Satisfaction & Q8 \\
\hline Perceived quality & Q9 \\
\hline Perceived price & Q10 \\
\hline Perceived risk & Q11,Q12 \\
\hline Brand and marketing related factors & Q13-Q17 \\
\hline
\end{tabular}

Some of the factors that considered in this study require some further definition.

\subsubsection{Intention}

Purchase intention refers to the willingness of a consumer to buy a certain product [13]. There is an obvious relationship between brand image and purchase intention and advertisement can play a major role to create and increase positive brand image on consumer. Shifting from one brand to 
International Journal of Managing Information Technology (IJMIT) Vol.12, No.3, August 2020

another due to advertisement is also possible [14], except those who purchase from a brand frequently and resist switching to other brand.

Customers normally converge to those brands that they think having the right price quality relation. When consumers get satisfied with a particular brand product, there will form a positive attitude towards that brand and later, will have an impact on purchase intention, eventually an increase in actual purchase [15].

\subsubsection{Perceptions}

Perception is a process of how individual see and make sense of their environment [16]. It defines how people select, organize and interpret information. Whenever a consumer intend to buy a product, the decision is actually depend on the perception he possesses about that particular product.

Perception of product can be sub-divided into perceived price, perceived quality, perceived risk and perceived value.

\subsubsection{Perceived price}

In general, price is the amount of money a consumer need to expense to obtain the product. Price can be classified as objective price and perceive price [17]. Objective price refers the actual price of the product while perceive price depends on the perception of individual customer about the price in relation to the quality of the product. When perceived price with respect to objective price is different, a positive or a negative impact on the buying decision may happen.

\subsubsection{Perceived quality}

Quality is defined as evaluation of excellence and superiority of the product from the consumer point of view [18].

\subsubsection{Perceived risk}

Perceived risk can be explained as consumers' doubt about the result of their buying decisions [19]. Hence, when a customer perceives higher level of risk about a product, he may decide against buying that product. Customers who purchase familiar brands normally have reduced purchasing risk [19].

\subsubsection{Perceived value}

According to [17], perceived value is the customer's overall assessment of the utility of a product base on perceptions of what is received and what is given. Where give component represents price, and receive component refers to quality.

\section{Data Analysis AND Result}

Based on the responses of the Questionnaire, a number of graphs have been generated by the Google form tool and those resulted graphs are analyzed in the following subsections: 
International Journal of Managing Information Technology (IJMIT) Vol.12, No.3, August 2020

\subsection{Demographic factors $(\mathrm{Q} 1, \mathrm{Q} 2)$}

Figure 1 illustrates that most of the responders' age are within the range of 18 and 25, and are university students as mentioned. Only a few percentages of the responders are between 26-35, under 18 and above 50 .

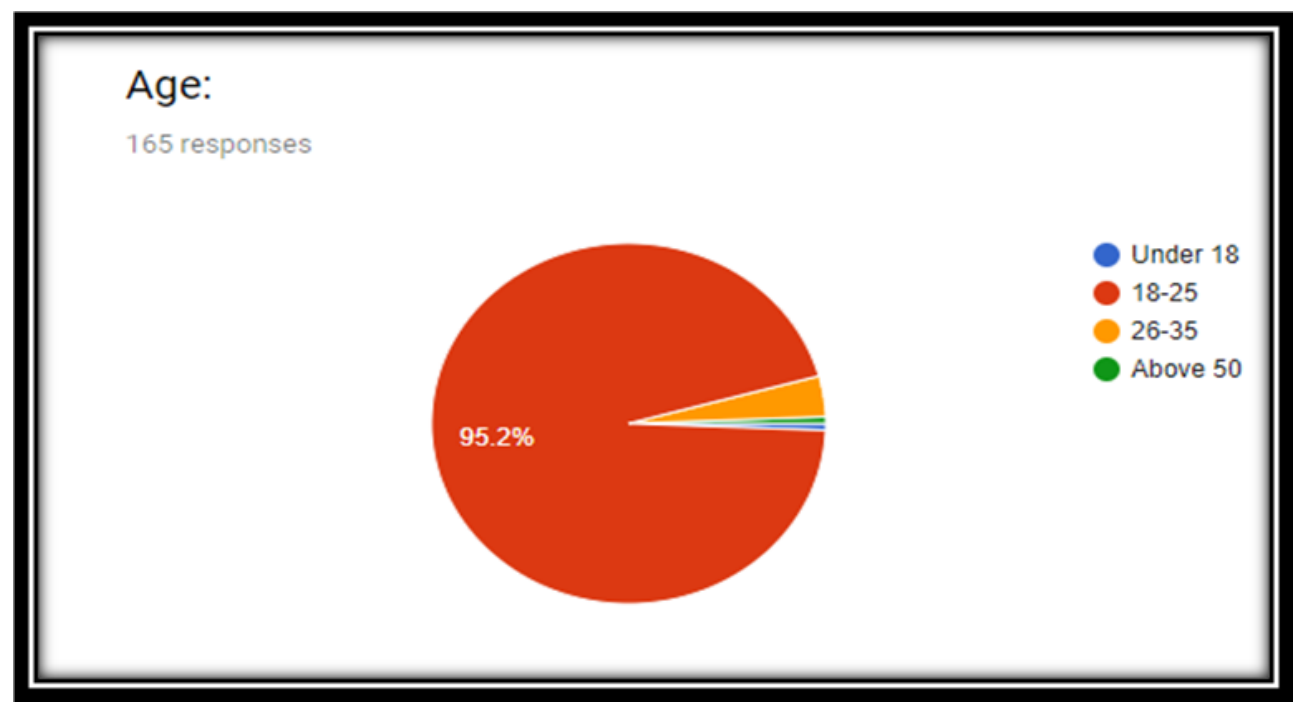

Figure 1. Age (Q1)

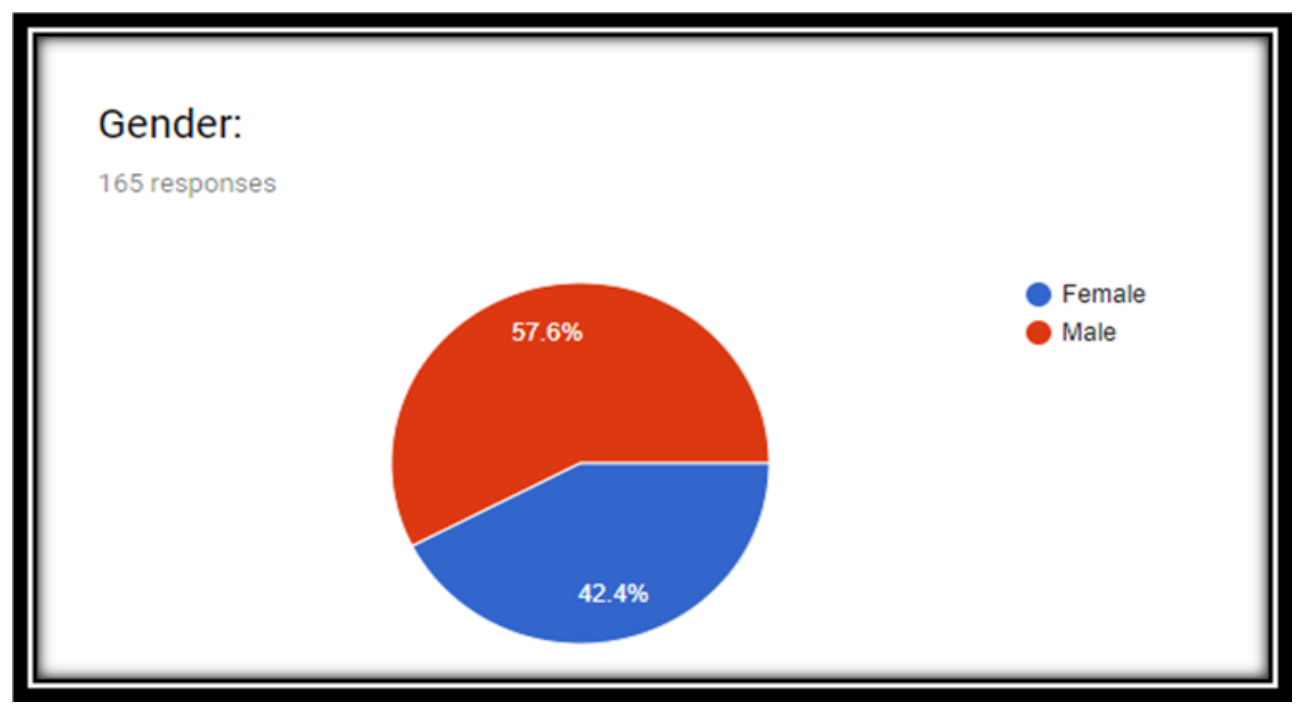

Figure 2. Gender (Q2)

As indicated by Figure 2, 57.6\% of the responders are male and remaining $42.4 \%$ of them are female. 


\subsection{Classify Respondents (Q3, Q4)}

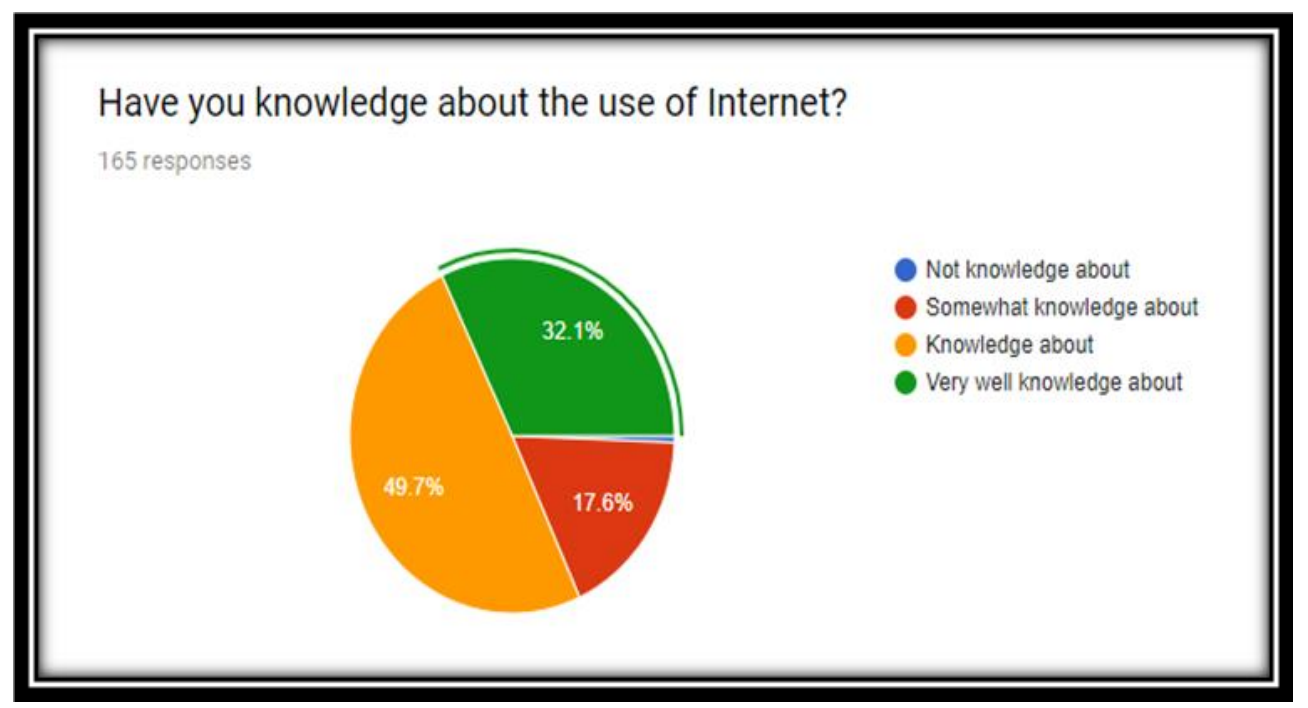

Figure 3. Familiarity with the Internet (Q2)

Figure 3 clearly shows that almost all of the responders have at least somewhat knowledge about the Internet. Specifically, about $32.1 \%$ of them have very well knowledge about the Internet, while $49.7 \%$ have moderate knowledge and $17.6 \%$ have somewhat knowledge. Number of responders with no knowledge of the Internet at all is ignorable.

However, this high percentage of literacy for internet usage does not guarantees that they are experienced with online shopping also.

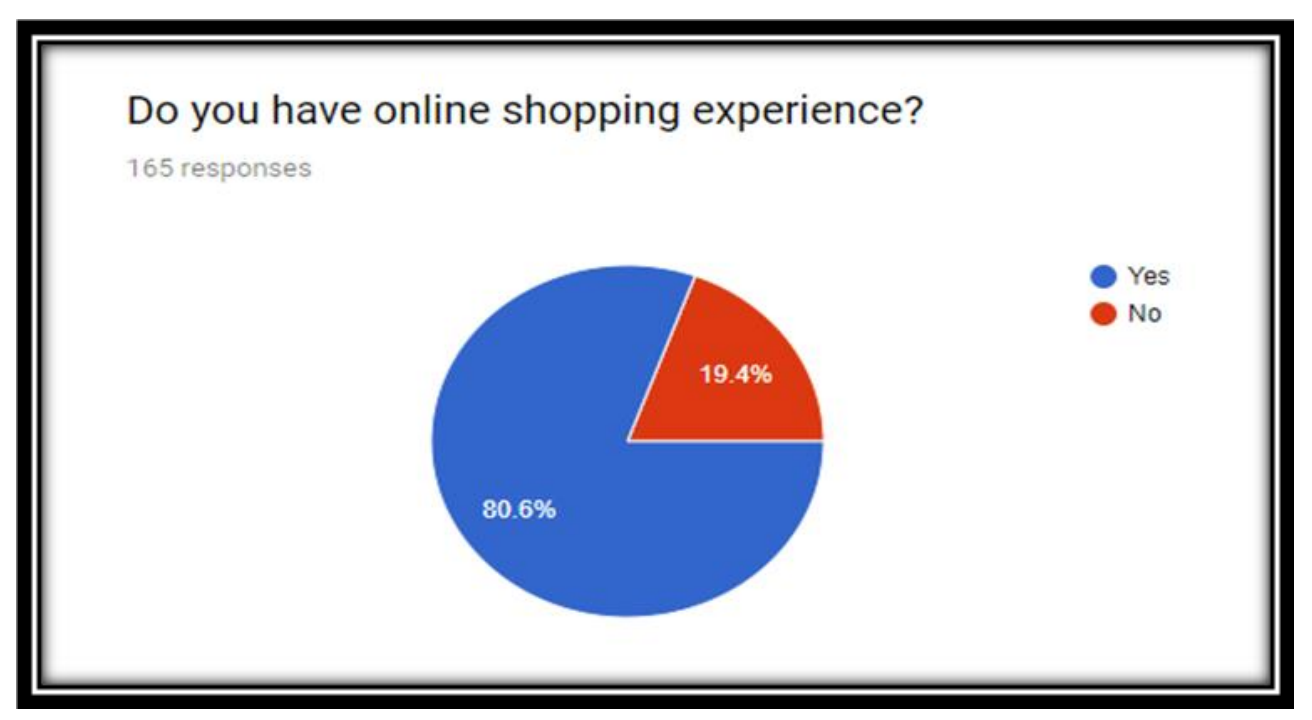

Figure 4. Online shopping experience (Q4)

As it can be seen from Figure 4, $80.6 \%$ of the respondents have shopping experience using the Internet and remaining have no shopping experience which is $19.4 \%$ to be specific. 


\subsection{Loyalty to Online Shopping (Q5)}

This question was formulated for identifying the level of trust and loyalty of the responders on online shopping. In this case, only a fraction of percent $(0.6 \%)$ said that they always buy from online, $13.3 \%$ responded that they often buy from online, $69.1 \%$ responded they sometimes buy products from online. There are also $17 \%$ of responders who never bought any product from online.

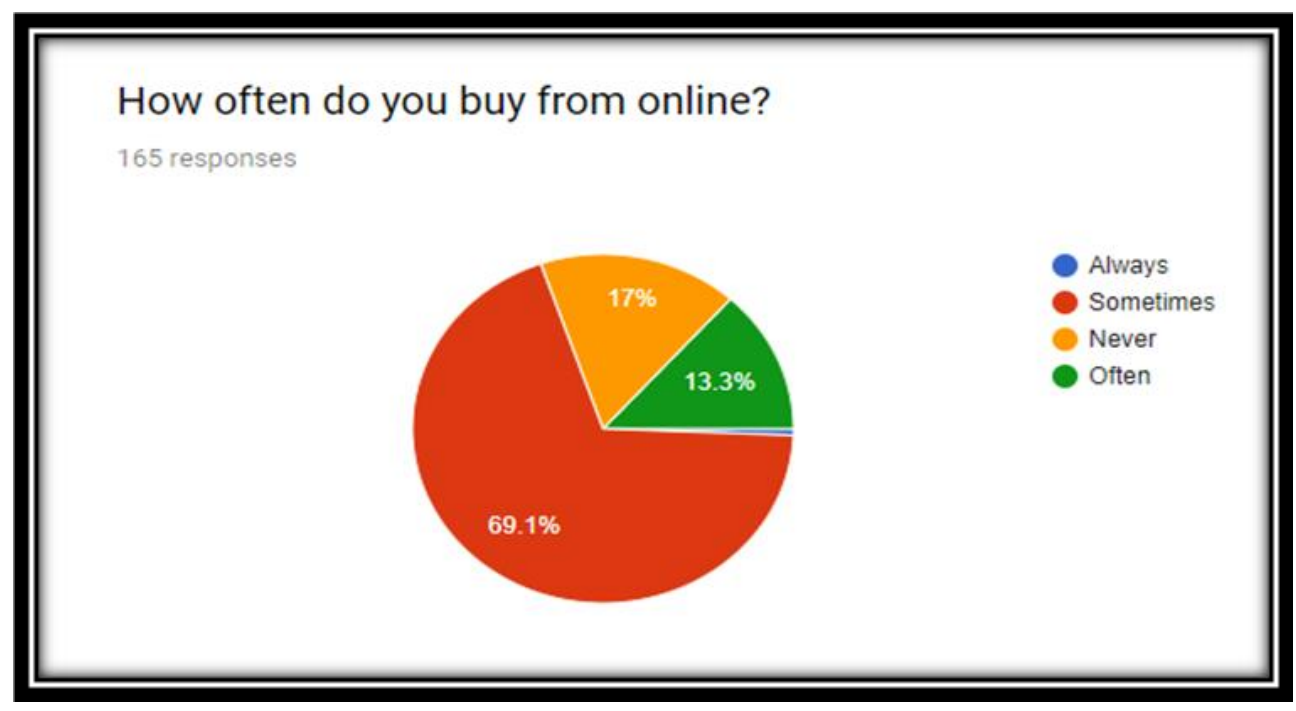

Figure 5. Loyalty

The low percentage of regular online shoppers is quite acceptable for a developing country like Bangladesh. But it is growing very quickly as the usage of Internet having a very rapid growth in this area.

\subsection{Intention (Q6, Q7)}

What make you decide to buy from online?

165 responses

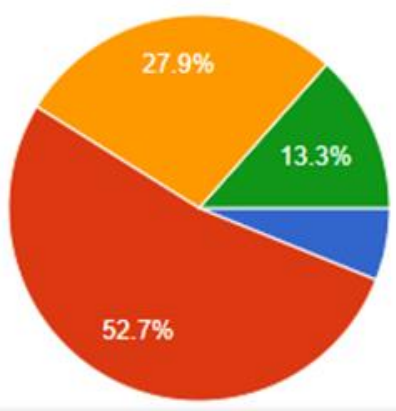

Figure 6. Intention (Q6) 
International Journal of Managing Information Technology (IJMIT) Vol.12, No.3, August 2020

Consumers normally intend to purchase a product when they think there is a right price quality relation. From the responses of our survey, it is seen that $52.7 \%$ of the responders buy from online due to availability of variety of options, $27.9 \%$ for acceptable quality, $6.1 \%$ for low price. $13.3 \%$ of the respondents have said that they are not sure about it, and represent those who are not familiar with online shopping. The least percentage of respondents has chosen low price, which verifies the fact that only price alone does not matter to customer anymore while buying products. It is obvious that consumers who are satisfied with the product will have a positive attitude towards the brand and consequently will also have impact on purchase intention.

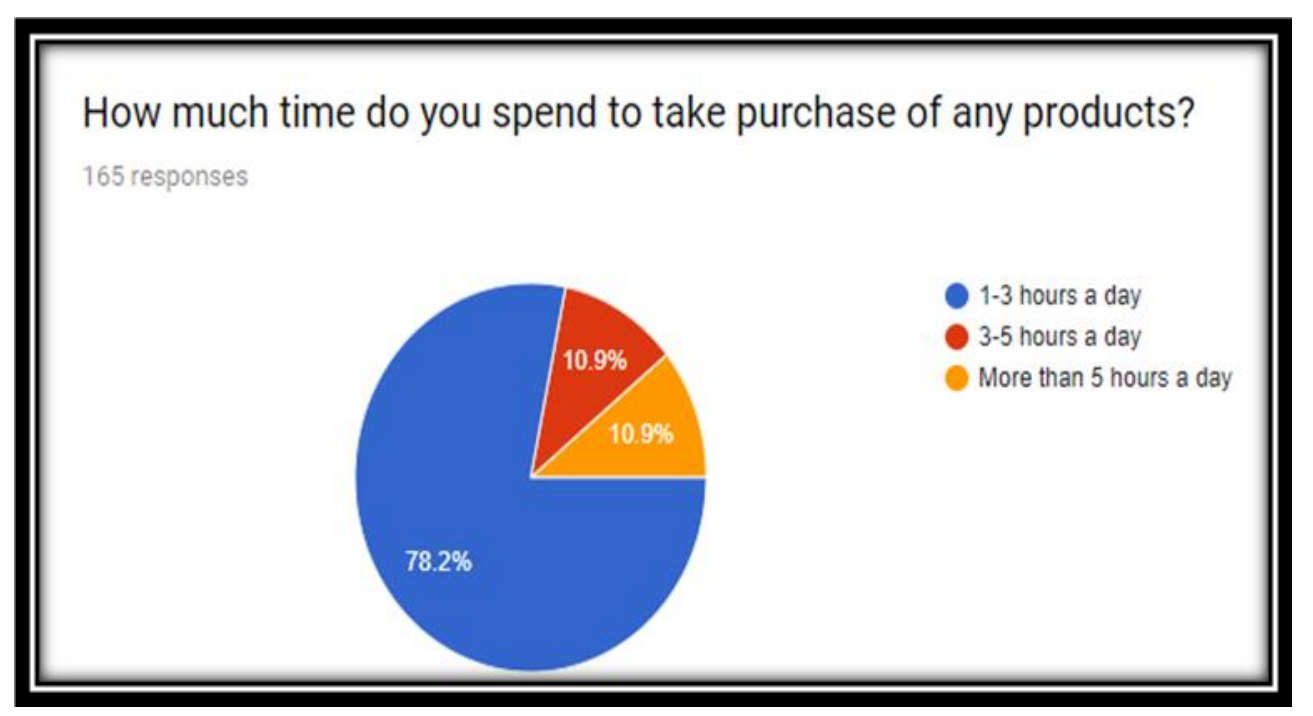

Figure 7. Time $(\mathrm{Q} 7)$

Time is an important factor in case of Digital marketing. The amount of time one takes to purchase a product provides further information about his intension while buying products. People spending more time clearly are more concerned for choosing the best product with the lowest possible price. It also indicates the marketers that what length of advertisement is tolerable to the customers.

According to the findings, maximum respondents, specifically $78.2 \%$, spend 1-3 hours of a day during their free time. $10.9 \%$ of the responders spend 3-5 hours a day and the same percentage also said that more than 5 hours a day they take for purchasing. It indicates that consumers expense a fare amount of time for collecting information about a product before taking any purchase decision. This collected information may increase their knowledge and assurance on brands' attributes and benefits which eliminate their confusion about any particular brand. Once they obtain the required information on various brands, subsequent purchases of those brands products may require less amount of time. 


\subsection{Satisfaction $(Q 8)$}

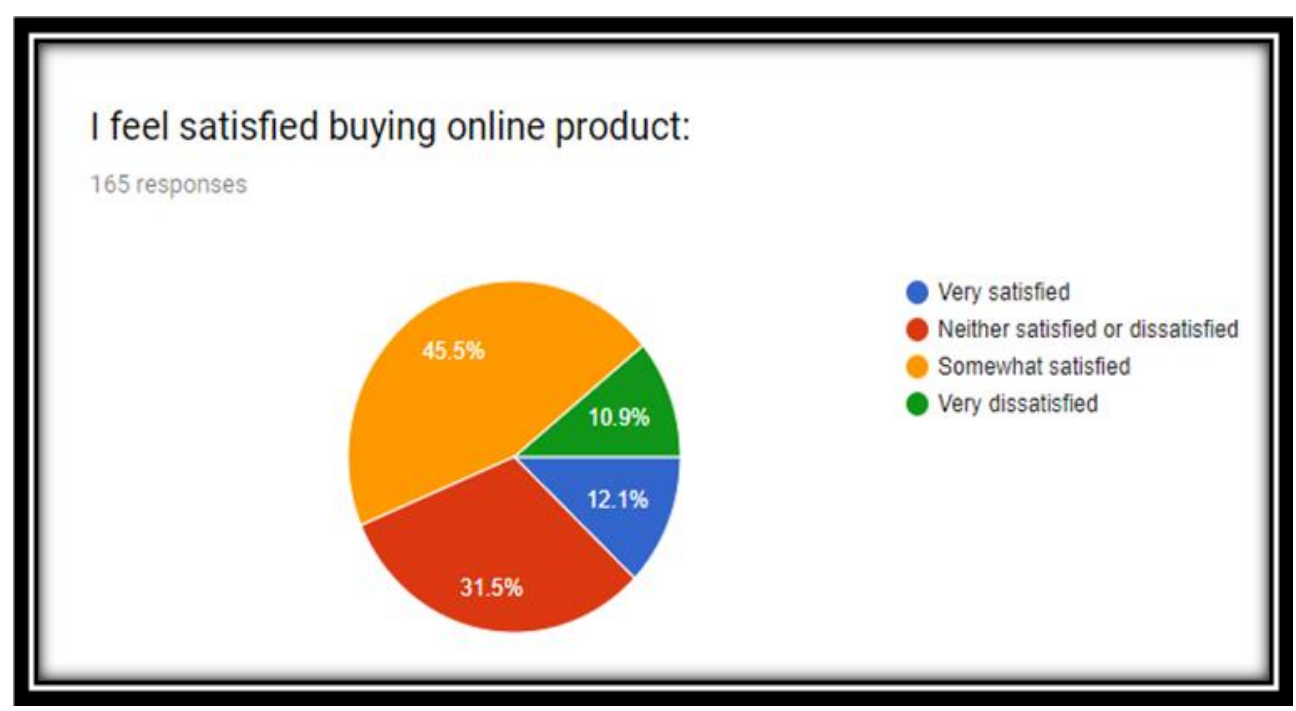

Figure 8. Satisfaction (Q8)

Consumers are somewhat satisfied with buying online products, based on the response of $45.5 \%$ of the responders; while very satisfied are $12.1 \%$. From the theory of satisfaction, it is previous experience or accumulated experiences over time that makes someone satisfied or dissatisfied about a particular product of a particular brand shopped online. The result indicates considerable proportion of buyers gave positive evaluated judgment on products based on their experience, in contrast to only $10.9 \%$ are dissatisfied buyers. The remaining $31.5 \%$ thought that they were neither satisfied nor dissatisfied.

\subsection{Perceived Quality (Q9)}

Almost $77.6 \%$ of respondent agreed (46.7\% agreed and $30.9 \%$ somewhat agreed) that products which have low price would not be guaranteed for the quality. While only $17 \%$ of respondents disagree with this statement. Remaining few of respondents are somewhat disagree. These responses are showed in Figure 9.

In order to maintain low price of products, manufacturers normally pick out some of the ingredient content and provide simpler package fashion. Regarding quality, every brand has a standard set of quality measures for products and they ensure that the quality meets certain requirement balance. While purchasing products of a well known brand or brand products with previous satisfactory experience, consumers feels safe and guaranteed even if the product price is low than the other brands. That means additional trust may be felt if it comes from a popular brand. 
Do you think quality of low price products would not be guaranteed? 165 responses

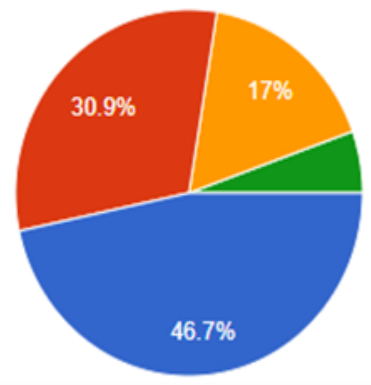

Agree

Somewhat agree

Disagree

Somewhat disagree

Figure 9. Perceived quality (Q9)

\subsection{Perceived Price (Q10)}

This question formulate about how the association between low price products and reputation of retailers' influences the perceived price of products. After finding responses from sample, it is seen that $75.2 \%$ (strongly agree $18.8 \%$ and $56.4 \%$ are somewhat agree) feels well known retailers are trustworthy for buying low price products. Remaining of the responders does not feel so or have no idea about this.

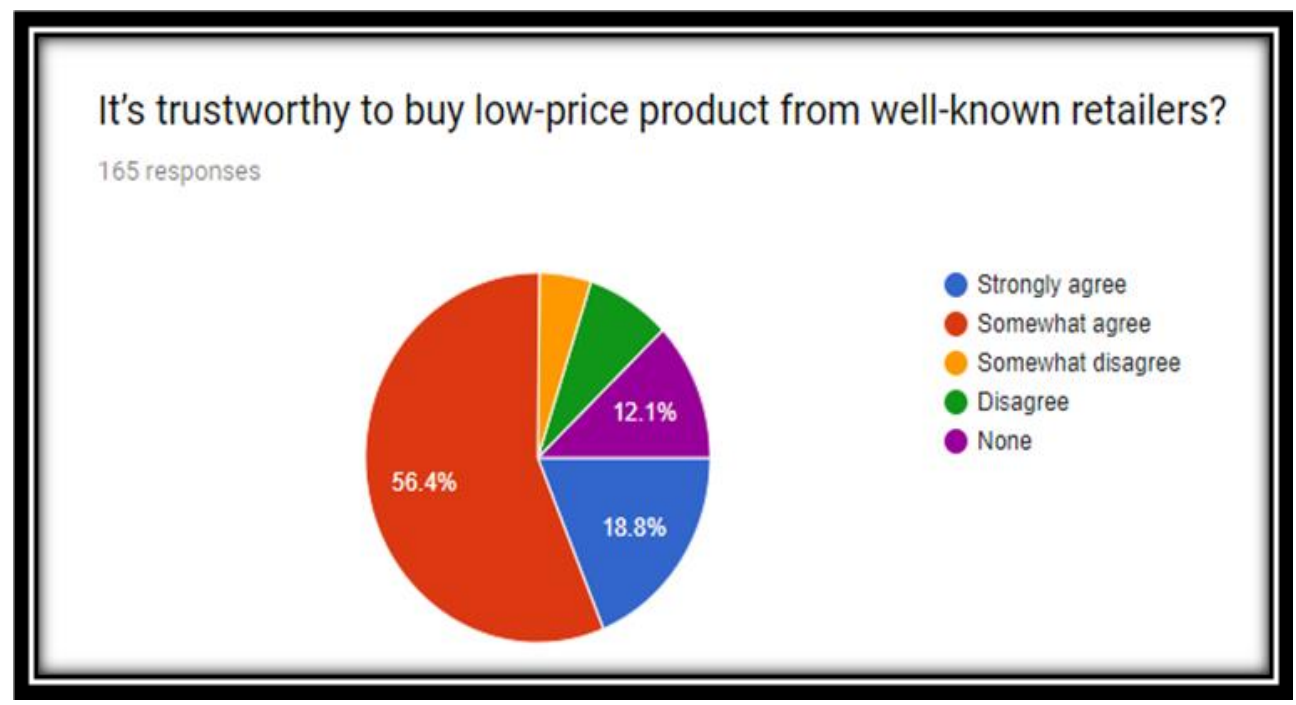

Figure 10. Perceived price (Q10)

The overall response of this question illustrates that the retailer reputation has significant influence on consumer decision making when they buy product. Majority consumers tend to hold positive attitude to low price product, providing that they are provided by well-known retailers. Consumers interpret brand from organization perspective and consider the organization as the whole, including people, value, programs etc., those lie behind the brand of product. That means 
International Journal of Managing Information Technology (IJMIT) Vol.12, No.3, August 2020

the retailers can also play an important role in making customer brand relationship. The trust of customers is one of the most important assets for retailers companies.

\subsection{Perceived Risk (Q11, Q12)}

It is seen from Figure 11 that high percentage of respondents said that online marketing has drawbacks, which is $86.7 \%$ and $13.3 \%$ have said that they do not find any drawbacks.

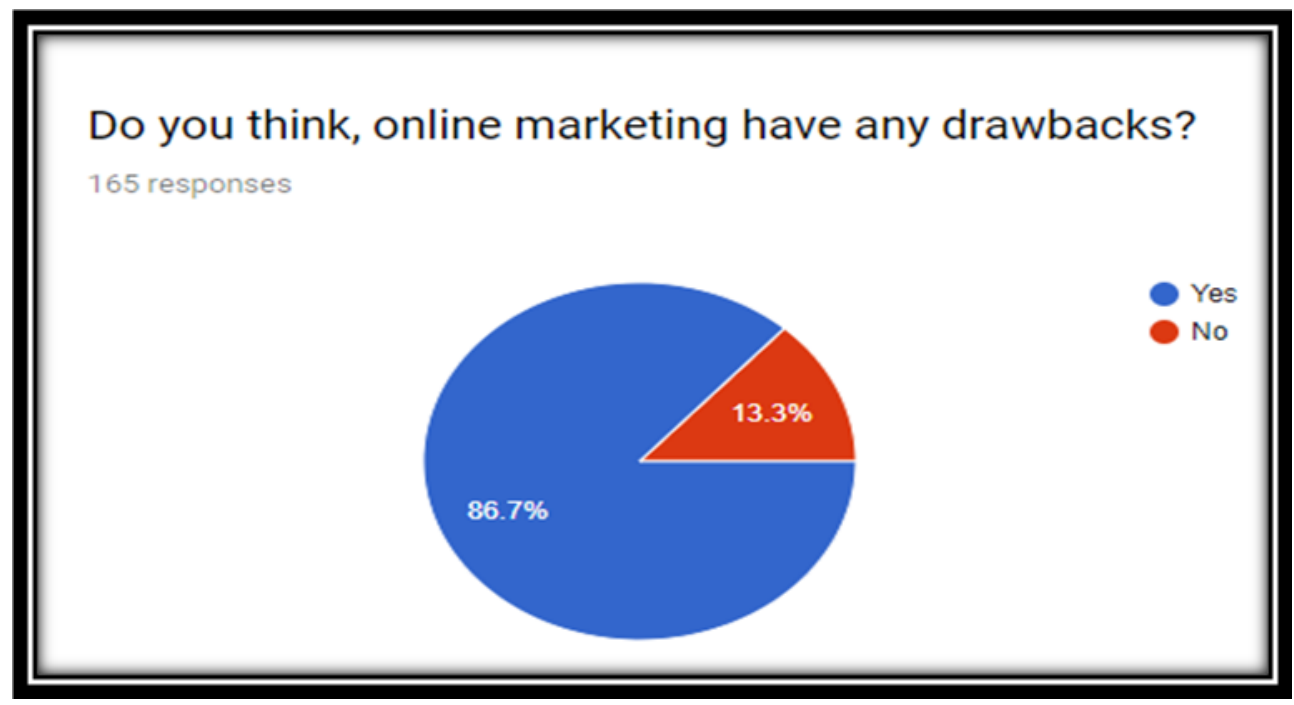

Figure 11. Perceived risk (Q11)

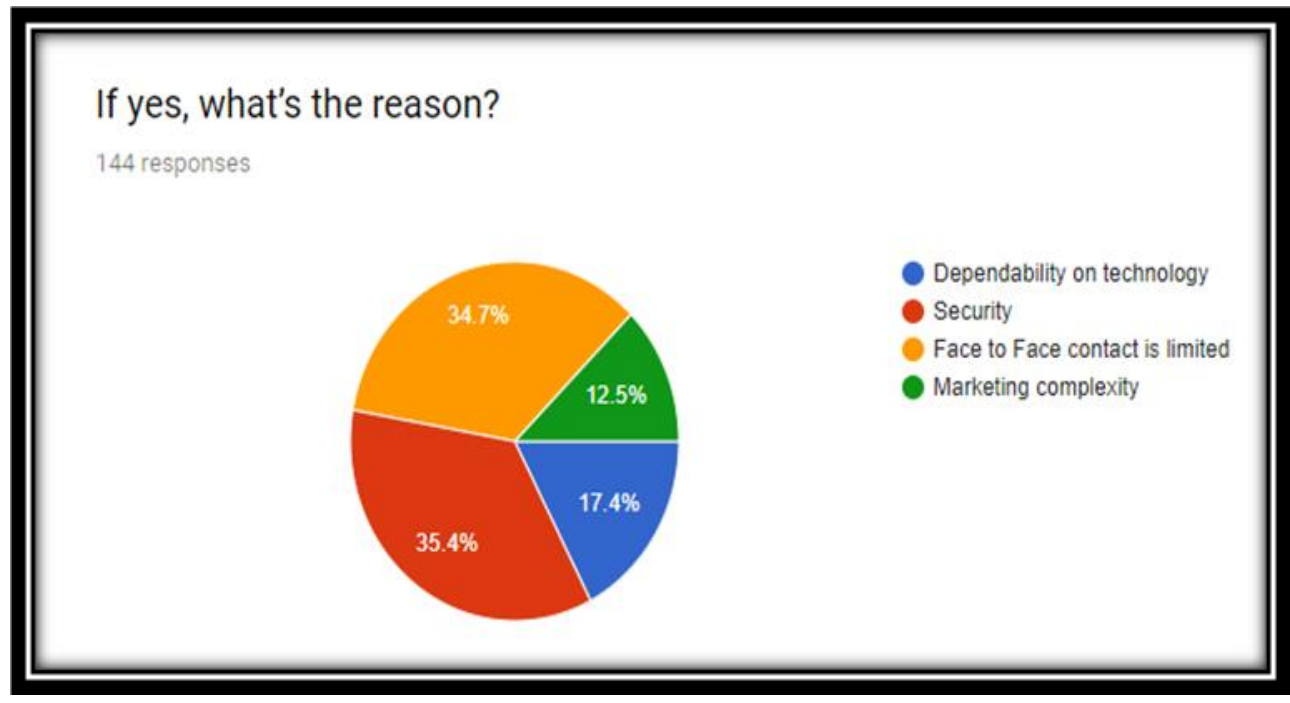

Figure 12. Perceive risk factors (Q12)

According to the responses, security and lack of face to face contact are the main drawbacks for online shopping over traditional shopping. Specifically, 35.4\% of the respondents chosen security as the drawback, while $34.7 \%$ chosen lack of face to face communication. $17.4 \%$ responded that too much dependency on technology makes them feel uncomfortable with online shopping. 
International Journal of Managing Information Technology (IJMIT) Vol.12, No.3, August 2020

Remaining of the respondents found that shopping complexity is greater in online shopping, which may be due to lack of knowledge about Internet and resulted browsing inefficiency.

Based on the question of retailer's trustworthiness, it is obvious that if the consumers are familiar with the brand and have good experience with particular retailer they perceive less amount of risk.

\subsection{Brand and Marketing related factors (Q13 - Q17)}

The cooperative objective of the study was to establish the impact of Internet advertising in Bangladesh. The respondents were asked whether they like online advertsing or not. As illustrated in Figure 13, 55.2\% of them agreed that they like those advertisements, which reflects that obviously online advertisements influnce their purchase decisions. $39.4 \%$ of the respondents responded against advertisement.

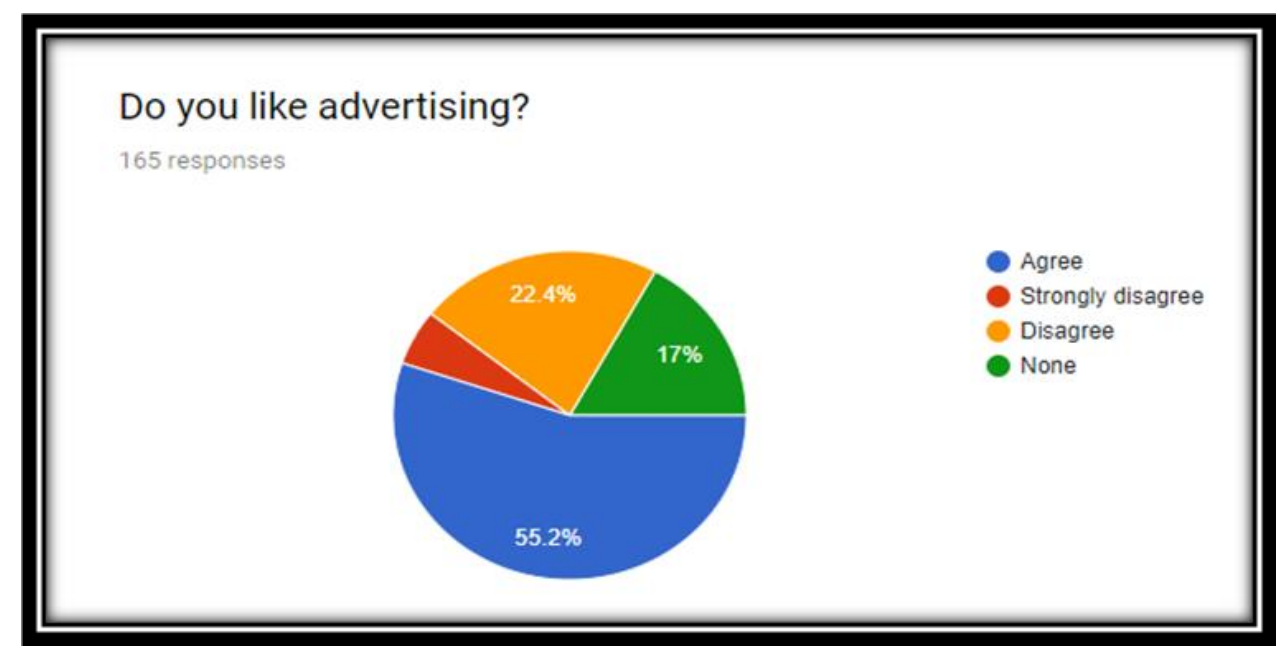

Figure 13. Impact of advertising (Q13)

Clearly the intention of them while surfing the Internet not to see the ads, but they do not have any other options but to see them when they are Interstitial Adverts, Pop - up ads or Floating ads. Ads those are not irritating may attract them, but when presence of ads irritates the customers may create negative feelings about that product being advertised. 
What mode of advertising influences you to buy any product?

165 responses

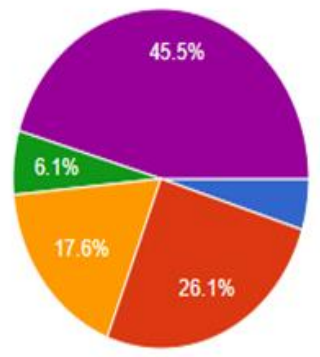

Magazines and newspape

Online advertisements

- Friends and relatives

- TV Commercial

- Social media, blogs, forums, social networking sites

Figure 14. Impact of different forms of advertising (Q14)

Respondents were asked to indicate the form of advertising that mostly influence their purchase decision about a product. The goal was to determine the relationship between internet advertising and purchase decision.

The highest number of respondents $(45.5 \%)$ said that they get influenced to buy a product based on information provided by social media, blogs, forums and social networking sites. $26.1 \%$ respondents are influenced by online advertisements on other platforms such as games, websites etc. $17.6 \%$ respondent are influenced by friends and relatives. $6.1 \%$ are influenced by TV commercial and remaining $4.7 \%$ respondents are influenced by newspapers and magazines.

This depicts that traditional form of advertising has an edge over Internet advertising in terms of consumer attraction. Internet advertising has become the most effective form of advertisement for influencing purchase decision of the customers.

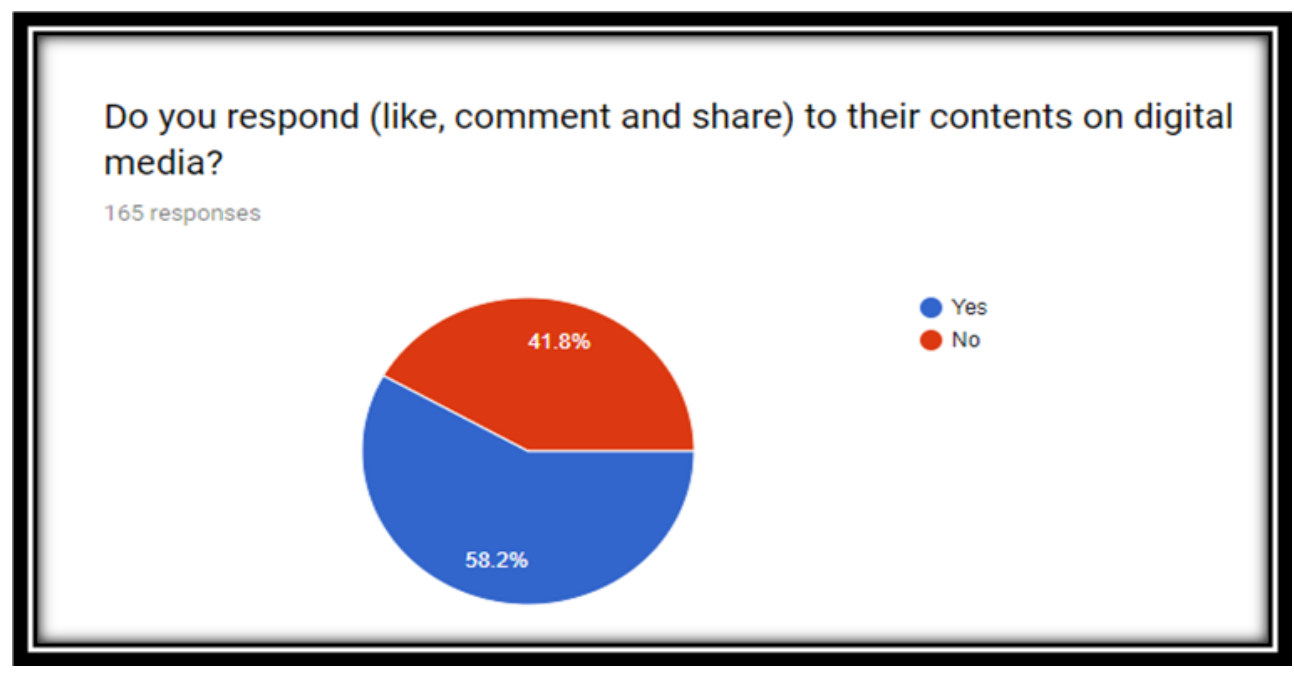

Figure 15. Feedback of customers (Q15)

According to survey findings, $58.2 \%$ respondent said that they respond to their contents on digital media by like, comments, sharing. That means they follow their favourite brand online and like 
contents appear there, also share those in the digital media. By sharing, they are also promoting the brand. Comments from the consumers can be either positive or negative. That means comments can act positive negative both ways for the products. All these feedback helps others to get idea about the products. However, $41.8 \%$ of the respondents also said that they do not respond to the contents on digital media.

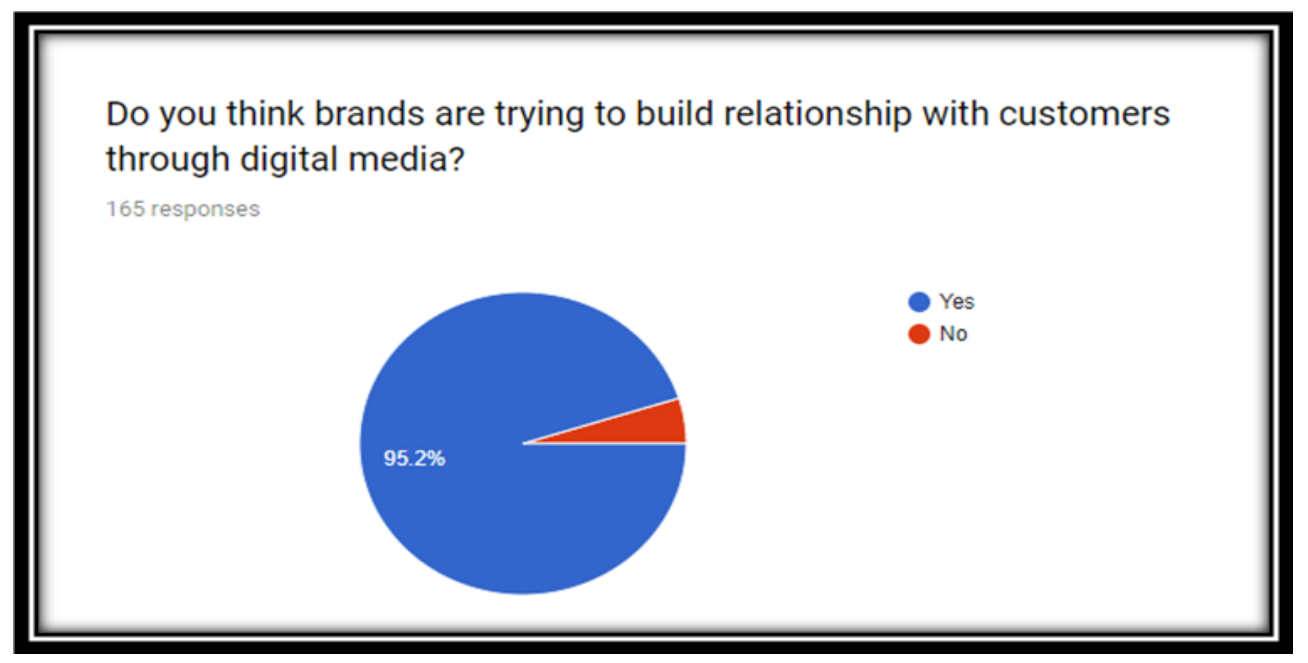

Figure 16. Brand customer relationship (Q16)

As Figure 16 illustrates, the use of digital marketing for building brand customer relationships is quite evident as $95.2 \%$ of the responders acknowledged that. Remaining $4.8 \%$ of responders do not feel so. So this is clearly shows that digital marketing platform providing brands a vast channel to reach customers which is being accepted by the customer in a positive manner.

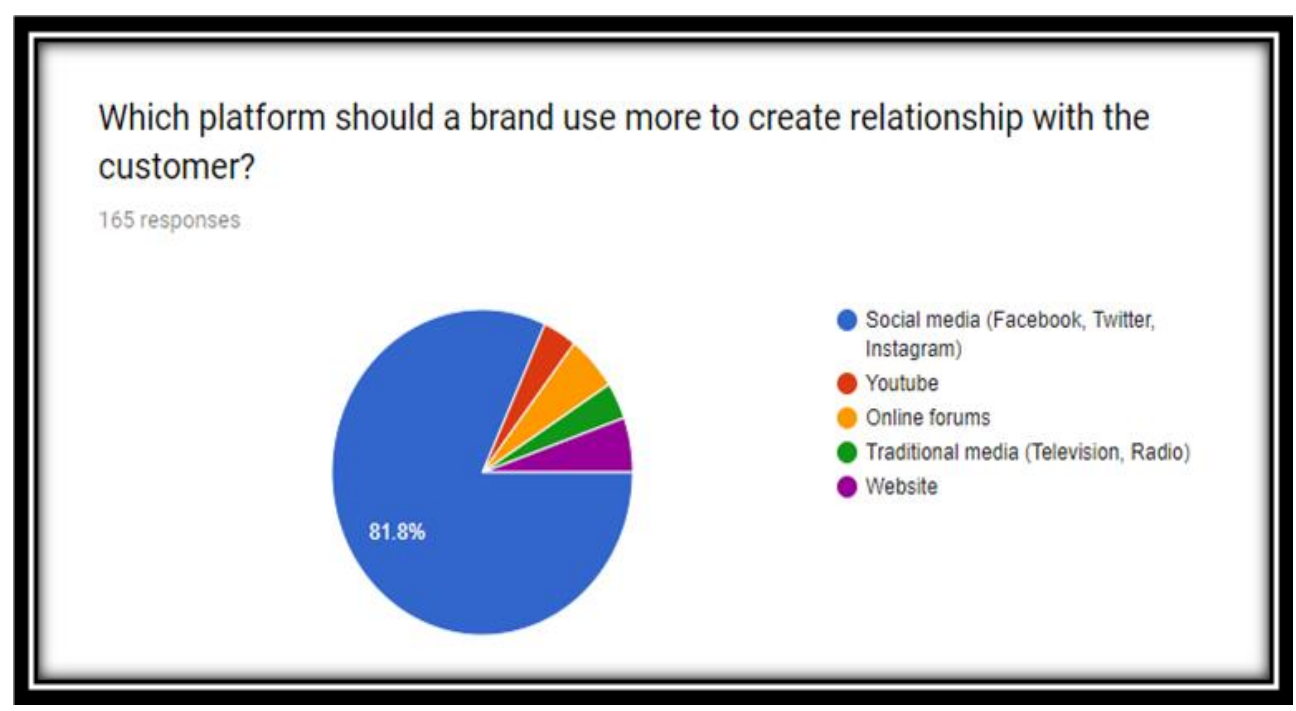

Figure 17. Recommended platform (Q17)

According to the study, customers prefer different social networking sites like facebook, twitter, instagram as the platform to create relationship with brands. At present, facebook has become undoubtedly one of the most popular social networking site throughout the world where people spend huge amount of their day time. People of Bangladesh are also no exception. This may be 
International Journal of Managing Information Technology (IJMIT) Vol.12, No.3, August 2020

the reason why $81.1 \%$ of the respondents chose the option Social media as their preferred platform for creating relation with brand. Another evergrowing platform is Youtube, which is becoming popular in Bangladsh also. Youtube could be the next game here in terms of customer brands relationship building. Along with Youtube, as Figure 17 illustrates, many other platform like online forums, traditional media (television, radio), website etc can be used for building the relationship but are not as effitive as the social media.

The concept of online shopping and digital marketing is still at a young age in Bangladesh, but since it is not an isolated part of the world, it is growing rapidly like other parts of the world. The goal of this survey was to reveal the pattern of this growing concept, to provide the characteristics of online customers in this region, and also to suggest what may be the most effective way for the brands to reach their targeted customers, or to build a strong brand-customer relationship. Findings illustrate that people experienced online shopping tends to get loyal to this kind, but do not like to spend too much time. Advertisements obviously influence them positively, as long as they not get annoying during their spent time. According to the responses, social media acts as the most effective way for brands to create and maintain relations with customers, while trustful brand customer relation can be build up through well known online retailers.

\section{Limitation OF THE STUDY}

This study is purely based on survey and targeted only respondents of a specific age. In some cases, lack of understanding of the questionnaire may result in inaccurate response since there was no face to face discussion. The number of respondents is also a limitation of this study. No statistical analysis was employed. The age restriction was imposed intentionally for counting only those who are experienced with online shopping actually.

\section{Conclusion}

The present era is an era of interactions. There is no way only quality of products ensuring the successful marketing of that product. Customers prefer best possible product by consuming least possible time. The terms "quality" and "price" are being literally replaced by perceived quality and perceived price. More people a brand reaches with its product, the chance of success of that product becomes higher. Digital marketing provides an ample opportunity on this purpose. But poor digital marketing strategy not only eliminates this advantage but also can be harmful to the brand image. This survey study may provide a general guideline between successful and unsuccessful digital marketing for this region. Product specific guideline requires further specific study correlating the product. For getting more realistic assumptions about the trend of growth and efficient digital marketing strategies, interactive involvement of huge number of respondents and vast statistical analysis on collected data must be performed.

\section{REFERENCES}

[1] Banerjee, Baisakhi, (2015) "Traditional vs.social media as a marketing communications tool in FMCG sector in India", Asia Pacific Journal of Research, Vol. 1, No. 21, pp 154-162.

[2] Velnampy T. and Sivesan, S., (2012) "Customer relationship marketing and customer satisfaction: A study on mobile service providing companies in Srilanka", Global Journal of Management and Business Research, Vol. 12 No. 18, pp 1-7.

[3] Karam, A. Ali and Saydam, Serdar, (2015) "An analysis study of improving brand awareness and its impact on consumer behavior via media in North Cyprus (A case study of fast food restaurants)", International Journal of Business and Social Science, Vol. 6, No. 1, pp 66-80. 
International Journal of Managing Information Technology (IJMIT) Vol.12, No.3, August 2020

[4] Nuseir, Mohammed T., (2016) "Exploring the use of online marketing strategies and digital media to improve the brand loyalty and customer retention", International Journal of Business and Management, Vol. 11, No. 4, pp 228-239.

[5] Haider, Tashrifa and Shakib, Shadman, (2017) "A study on the influences of advertisement on consumer buying behavior”, Business Studies Journal, Vol. 9 No. 1, pp 1-13.

[6] Nahili, W. and Rezeg, K., (2018) "Digital marketing with social media: What Twitter says!," In Proceedings of 3rd International Conference on Pattern Analysis and Intelligent Systems (PAIS), Tebessa, pp 1-5.

[7] Amrita, S. M. and Mohan, R., (2016) "Application of social media as a marketing promotion tool A review," In Proceedings of IEEE International Conference on Computational Intelligence and Computing Research (ICCIC), Chennai, pp 1-6.

[8] Narayanan, K. S. and Suganya, S., (2019) "A review to find the best tool for promoting brands in India using digital marketing”, International Journal of Computer Applications, Vol. 178, No. 33, pp $38-41$.

[9] Išoraitè, Margarita, (2016) "Raising brand awareness through the Internet marketing tools", Independent Journal of Management and Production, Vol. 7, No. 2, pp 320-339.

[10] Ugonna, I. A., Okolo, V. O., Nebo, G. N. and Jeff O., (2017) "Effects of online marketing on the behaviour of consumers in selected online companies in Owerri, Imo State - Nigeria", International Journal of Business and Management Invention, Vol. 6 No. 6, pp 32-43.

[11] Mahalaxmi, K. R. and Ranjith, P., (2016) "A study on impact of digital marketing in customer purchase decision in Trichy", International Journal for Innovative Research in Science \& Technology, Vol. 2, No. 10, pp 332-338.

[12] Kumara, Vikas and Kaushik, Arun K., (2018) "Building consumer-brand relationships through brand experience and brand identification", Journal of Strategic Marketing, Vol. 2018, pp 1-21.

[13] Calvo-Porral, Cristina and Lévy-Mangin, Jean-Pierre, (2017) "Store brands' purchase intention: Examining the role of perceived quality", European Research on Management and Business Economics, Vol. 23, pp 90-95.

[14] Tariq, M. Irfan, Nawaz, M. Rafay, Nawaz, M. Musarrat and Butt, H. Awais, (2013) "Customer perceptions about branding and purchase intention: A study of FMCG in an emerging market", $J$. Basic. Appl. Sci. Res., Vol. 3, No. 2, pp 340-347.

[15] Jin, Byoungho and Suh, Y. Gu, (2005) "Integrating effect of consumer perception factors in predicting private brand purchase in a Korean discount store context", Journal of Consumer Marketing, Vol. 22, No. 2, pp $62-71$.

[16] Chris Fill, (2002) Marketing Communications: Contexts, Strategies, and Applications, $3^{\text {rd }}$ Edition, Financial Time Prentice Hall, 2002.

[17] Shintaputri, Ikaningrum, and Wuisan, A. Jane, (2017) "The impact of perceived price towards perceived value through the mediation of perceived quality: A case of brand $\mathrm{X}$ smartphone in Indonesian middle-class customers", iBuss Management, Vol. 5, No. 1, pp 29-42.

[18] Snoj, Boris, Korda, A. Pisnik and Mumel, Damijan, (2004) "The relationships among perceived quality, perceived risk and perceived product value", Journal of Product \& Brand Management, Vol. 13, No. 3, pp 156-167.

[19] Chaudhuri, Arjun, (2001) "A study of emotion and reason in products and services", Journal of Consumer Behavior, Vol. 1, No. 3, pp 267-279.

[20] Aulia, S. Akbar, Sukati, Inda and Sulaiman, Zuraidah, (2016) "A review: Customer perceived value and its dimension”, Asian Journal of Social Sciences and Management Studies, Vol. 3, No. 2, pp 150162.

\section{AUTHORS}

Farjana Akter obtained her B.Sc. (Engg.) degree from the Department of Information and Communication Engineering of Noakhali Science and Technology University, Bangladesh in 2019. Currently she is pursuing her M. Sc. degree from the same department in the same university. She is highly dedicated to research based study. Her research interest includes big data analysis and machine learning. 
International Journal of Managing Information Technology (IJMIT) Vol.12, No.3, August 2020

Zayed- Us- Salehin obtained his B.Sc. (Engg.) degree from the Department of Computer Science and Telecommunication Engineering of Noakhali Science and Technology University, Bangladesh in 2010. He has completed his M. Sc. (Engg.) from the same Department and University in Telecommunication Engineering in 2015. He is a faculty member of Dept. of Information and Communication Engineering, Noakhali Science and Technology University, Noakhali, Bangladesh since May, 2013 and has been serving as an Assistant Professor in that department since 26th May, 2015. His research interest includes wireless communication systems and networks, mobile WiMAX networks, speech recognition systems, machine learning etc.

Abul Kalam Azad received his B.Sc. (Engg.) degree from the Department of Computer Science and Telecommunication Engineering of Noakhali Science and Technology University, Bangladesh in 2010; and has completed his research-based Masters degree from the Institute of Information and Communication Technology of Bangladesh University of Engineering and Technology, Bangladesh in 2016. He has been serving as a faculty member in the Department of Computer Science and Telecommunication Engineering of Noakhali Science and Technology University of Bangladesh since 2012. His research interest includes on wireless sensor networks, IoT, Network security and data mining.

Sultana Jahan Soheli currently working as an Assistant Professor at Department of Information and Communication Engineering, Noakhali Science and Technology University, Bangladesh. She completed her Bachelor and Master in Information Technology from Jahangirnagar University, Bangladesh. She has her research interest in the field of Internet of Things, Artificial Intelligence, Networking and Cloud Computing. 